\section{0 year DCP celebration at the Eastman}

To celebrate its $60^{\text {th }}$ anniversary, the Eastman is hosting a celebratory congress for the whole dental team. The event will take place on Thursday 3 and Friday 4 April 2008 in central London.

Richard Welfare will run a session aimed specifically at DCPs titled 'Is there a role for DCPs in implant treatment?' More patients than ever before are being rehabilitated with implant retained prostheses, and the provision of this type of treatment affects the whole team from the dental nurses, technician and clinician to the hygienist, therapist and other support staff. Mr Welfare will update the congress on current thinking for a successful treatment outcome.

Other speakers at the congress will address 'Why should we register with the GDC and what about CPD?' (Julia Brewin); 'Are bugs important?' (Vanya Gant); and 'Does the design of the restoration matter?' (Ken Hemmings).

To book your team's place at the congress or for more information, visit www.eastman60.org.uk, email eastman60@ eastman.ucl.ac.uk or contact Victoria Banks on 02079051251 .

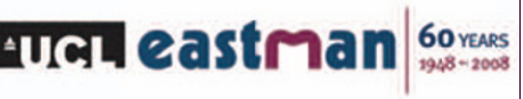

\title{
Bournemouth bowled over by BSDHT
}
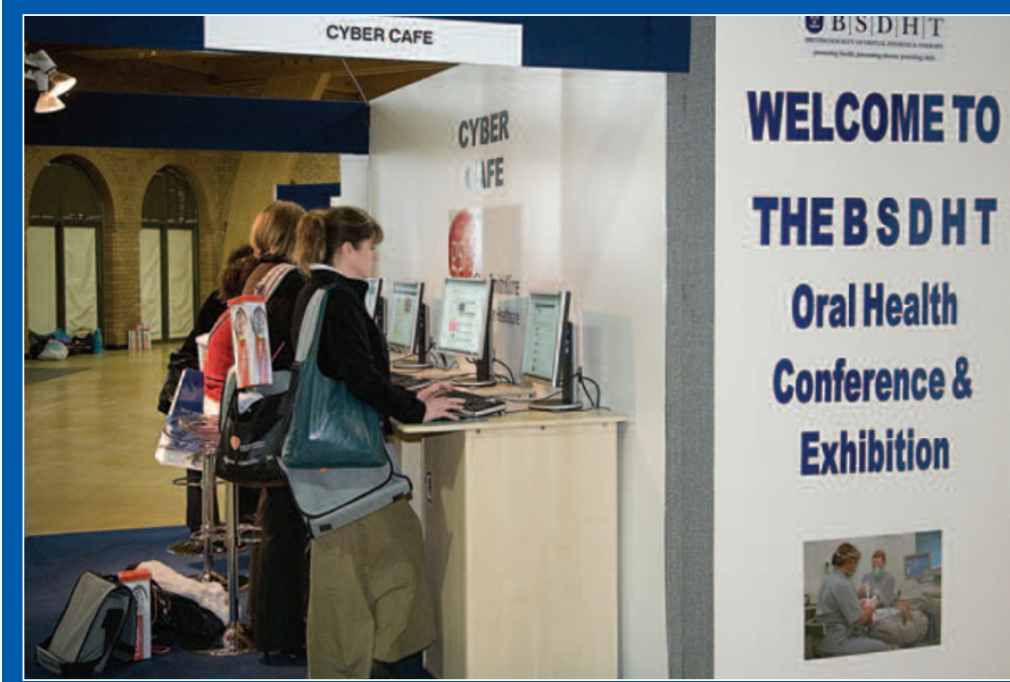

THEBSDHT

Oral Health

Conference \&

Exhibition

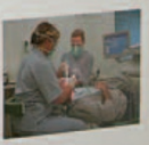

'A very informative, interesting and enjoyable day, enthused one delegate who attended the British Society of Dental Hygiene and Therapy's (BSDHT's) 2007 Oral Health Conference \& Exhibition.

Over 750 delegates from general practice, hospital and community services and the armed services flocked to Bournemouth International Conference Centre on 16-17 November. Key speakers included Professor David Bartlett who provided the latest scientific news, Conny Schweite who explained how hygienists function in Switzerland, and Graham Barnby who described how dental hygienists and hygienist-therapists can come to grips with the complexities of setting up their own practice.

A highlight of one presentation on the Saturday morning was scenes similar to a 1950s sci-fi film when all delegates were asked to don 3D glasses!

At the root of any BSDHT meeting is continuing professional development (CPD), and all delegates attending the conference in Bournemouth were presented with their CPD certificate before leaving.

General CPD was also contributed to with the trade exhibition, consisting of 49 stands, a new record for BSDHT.All of the latest product innovations were on display with opportunities to try them out and pick up samples to use back in the practice. An additional new feature of the exhibition was a cyber café which proved particularly well received.

The 2008 BSDHT Conference will be held in Edinburgh on 21-22 November. For advance details email enquiries@bsdht.org. uk or telephone 01452886365.

\section{Tempdent}

2007 was a successful year for Tempdent Recruitment and Training, who saw high levels of students passing exams with flying colours. The National Examining Board for Dental Nurses has just released the results for the National Certificate Examination, taken in November 2007. The national average pass rate was $58 \%$; Tempdent's pass rate was just above $87 \%(41 / 47)$.

\section{troiumpln}

'We would like to congratulate our students for their hard work and also our teaching team at Tempdent,' said Head Tutor Alison Doherty.

In 2007 students completed the full advanced apprenticeship NVQ level 3 qualification and attained above national average passes for the National Certificate qualification.
Tempdent are particularly proud that two of their students - Miss Christine Matteo and Mrs Magdalena Urbaniak-Ramessur - received the gold and silver awards respectively in the National Certificate out of 3,314 students across the country.

Tempdent is the only recruitment agency that offers qualification training for dental nursing and dental receptionists. They also offer CPD for the whole team through their training centre. For further information, see www.tempdent.co.uk or call 02083716700 . 